May 2020

\title{
Electronic Library Collections and Users with Visual Impairments: Challenges, Developments, and the State of Collections Policies in Academic and Public Libraries
}

Anthony D. Giovanni

San Jose State University and The Historical Society of Pennsylvania, digiovanni@hsp.org

Follow this and additional works at: https://scholarworks.sjsu.edu/ischoolsrj

Part of the Archival Science Commons, Cataloging and Metadata Commons, Collection

Velopment and Management Commons, Information Literacy Commons, Museum Studies Commons, Scholarly Communication Commons, and the Scholarly Publishing Commons

Acknowledgements

The author would like to acknowledge Mary Ellen Sloane, User Services Librarian for Basic and Applied Sciences at Middle Tennessee State University. Sloane is also a San Jose State University iSchool professor, and her feedback on a previous version of this paper led to its

\section{Recommended Citation}

DiGiovanni, A.M. (2020). Electronic Library Collections and Users with Visual Impairments: Challenges, Developments, and the State of Collections Policies in Academic and Public Libraries. School of Information Student Research Journal. 10(1). Retrieved from http:// scholarworks.sjsu.edu/ischoolsrj/vol10/iss1/5. 


\section{Electronic Library Collections and Users with Visual Impairments: Challenges, Developments, and the State of Collections Policies in Academic and Public Libraries}

The digital age has allowed for the creation of electronic resources that have revolutionized information retrieval for many. However, individuals with visual impairments (VI) face unique challenges with access to electronic resources that have yet to be overcome. Rayini (2017) states that one who possesses a visual impairment is someone who is "partially-sighted or completely blind." According to the World Health Organization (WHO) (2019), approximately 2.2 billion people worldwide have a visual impairment in some capacity. This includes individuals with acute and mild cases (para. 3). Given that the current world population stands at approximately 7.7 billion, the WHO's calculation is striking (United Nations, 2019). This is also a number that will likely continue to rise every day, whether visual impairments are congenital or degenerative. Between the complex nature of electronic resources to be interpreted via certain technologies (e.g., screen readers) and copyright laws inhibiting document reformatting, there is still difficulty when it comes to establishing truly equitable access to these resources for VI users. Therefore, an increase in awareness and action toward creating more accessible information environments is a must.

The ways in which libraries must develop increased equitable access for everyone is not only a desire or institutional mission, but in many places it is the law (Johnson, 2018, p. 128). For collections librarians, it is imperative to understand their users, and also what types of resources and formats are needed to bridge any gaps in accessibility. As a collection development policy is a librarian's guide to procure library materials, it is important that statements of resource accessibility are present. Overall, these policies provide users with an understanding of a library's collection scope, how the collection supports their mission, plans for maintenance, and a glimpse into an understanding of a library's users. In order to achieve this, librarians must conduct the appropriate research in their communities, which will also reveal any measures of accessibility to be considered. Once libraries make it a part of their collection policy to address accessibility, the discussion with vendors and publishers should be ongoing in regards to how they are working to remove the aforementioned technology, format, and legal barriers. In order to address the current accessibility gaps in libraries related to collection management and electronic resources, the research for this paper has identified the challenges VI users face with access; the developments in law to increase access; the state of collection development policies in academic and public libraries, and how they approach accessibility; and current electronic formats and products libraries can select to support accessible collections.

\section{Challenges with Access}

Emerging technologies have created opportunities for libraries to offer resources to their users through electronic formats, such as e-books, audio books, and electronic journal databases. These formats have created conveniences for library users all over the world by placing information at their fingertips. In regards to VI users, developments in technology have produced tools that increase accessibility to many of these resources (e.g., screen readers and braille keyboards). However, 
challenges still exist. Majinge and Mutula (2019) state that users with visual impairments are often "dependent on third parties to assist them to access electronic and print information resources" (p. 467), which leads to feelings of helplessness and frustration when their independence to access information is restricted by their disability. Furthermore, this challenge pertains largely to electronic sources accessed via the internet, such as academic databases. The ability for users to access information depends on the interface design, and whether it will allow users to apply appropriate technology to read information. Many times VI users must schedule time with an assistant to help them interpret the sources they wish to use (Majinge \& Mutula, 2019).

Harpur and Loudoun (2011) state that access for VI users will also depend on the case. In other words, some users may only need materials with enlarged print, whereas individuals who are completely blind will use tools that read texts in an audio format. This further depends on the type of materials the user seeks (e.g., scholarly journals, recreational ebooks). For VI college students who need to conduct research for a class, challenges arise when reader tools fail to recognize footnotes and endnotes, as well as ignore graphs and tables. As students are often tasked with pinpointing quotes and pages for references in their papers, this can prove difficult for VI users. For non-VI users, flipping back and forth between pages, and quickly scanning up and down is a convenience. Reader tools, however, are not as sophisticated to handle this task, and many times the software can make crucial mistakes when detecting words (Harpur \& Loudoun, 2011). For VI users who require enlarged print, many platforms through vendors such as Gale, EBSCO, Emerald, and Sage provide the ability for users to zoom in. In some cases this may be helpful, but for VI users that need color and contrast adjustments, the platforms do not provide the ability to do so (Mune \& Agee, 2016). Sage and Safari Tech, now Safari Books Online, offer alternative text descriptions for images and tables, which provide descriptions of these document components in order for reader tools to detect them (Mune \& Agee, 2016). As the aforementioned products represent a small percentage of platforms, there are questions as to why so few publishers and platforms offer equitable services to academic libraries.

Fitzpatrick (2014) states that publishers often refrain from licensing materials for equitable access, because the market does not support the need to do so. In other words, publishers do not find it cost-effective to create more accessible formats of materials in comparison to the percentage of people without print disabilities. If we consider WHO's global estimate (2.2 billion) of people with visual impairments and the world population ( 7.7 billion), these publishers' sentiments are difficult to grasp. At the same time, publishers have struggled with copyright laws, which reinforce barriers around creating more accessible formats (Fitzpatrick, 2014, pp 140, 142).

\section{Developments in Law}

In 2013, the Marrakesh Treaty was adopted by the members of the World Intellectual Property Organization (WIPO), which seeks to reevaluate and 
reconfigure current copyright laws in support of creating accessible formats of published materials. Since its adoption, many nations lagged in ratifying the Treaty, but as of October 2018 the European Union and the United States turned the corner in acceptance. It is important to note that before this development, the United States did have limited exceptions in its Copyright Act (Chafee Amendment), which allows for published materials to be recreated in accessible formats (Abbott, 2019). However, organizations and institutions must be approved to do so. The Marrakesh Treaty essentially works to achieve the same thing but on a world stage, and also broadens the terms of reproduction and access from "specialized formats" (e.g. specific to certain technologies) to "accessible formats." This change addresses any format that will support efficient access and needs (United States Copyright Office, 2019). As Olwan (2017) states, the Treaty "imposes on the contracting parties the obligation to provide works in accessible format copies in favor of beneficiary persons (also authorized entities), and also allows making any necessary changes to the work for that effect" (p. 181). In other words, this is a huge development that will change the game for publishers, but most importantly for the benefit of VI users.

Currently, Bookshare is the largest approved leading online library that has made over 748,000 ebooks available in accessible formats, and as a result of federal funding fueled by the Chafee Amendment (Bookshare, 2019-a). About 600,000 of these titles, according to Abbott (2019), have publisher permission to be shared. The recent United States ratification of the Marrakesh Treaty will allow Bookshare to share another 100,000 with the other participating 63 countries, as well as import books previously unavailable. In the view of the United States, this is a great advancement. For the world as a whole this is revolutionary, as $90 \%$ of the VI population exists in developing countries (Bookshare, 2019-a). Before Bookshare, however, the National Library Service for the Blind and Physically Handicapped (NLS) was a leader in assisting VI users with access.

Established in 1931, the NLS has only continued to expand and develop by offering a catalog of over 281,000 braille and audio materials in printed and downloadable formats, which can be accessed by participating libraries throughout the United States (NLS, n.d.). As of now, the NLS (n.d.) states that there are "55 regional libraries, 26 subregional libraries, and 16 advisory and outreach centers serving all 50 states, the District of Columbia, Puerto Rico, the U.S. Virgin Islands, and Guam" (para. 3) that participate in the exchange program where materials are shipped or downloaded. Similar efforts can be found in Canada with the Centre for Equitable Library Access (CELA), which was created to support public libraries across the country (CELA, 2019). Like the NLS, CELA has roots dating back to the early 20th century with the Canadian Free Library for the Blind (1907) and the creation of the Canadian National Institute for the Blind Library over a decade later (Ciccone, 2018). It is clear that the mission to provide equitable access for reading materials for VI users has its place in history, although widespread availability of materials has been sparse. The creation of special institutions certainly shows a great effort in the development of this 
process over time, but the overwhelming results to truly make things equal comes with establishing a level playing field at some point. An increase in the ratification of the Marrakesh Treaty can play a crucial role in this continuing development. For now, those taking part in the effort must focus on how to build the most equitable collections possible.

\section{State of Collection Development}

It is evident that although we have come a long way in an effort to increase access, there are still challenges to work through regarding how equitable resources can be to VI users. As we continue to move along to establish a path to fully accessible resources, libraries must consider all possible measures to ensure the collections they possess are as universally accessible as possible. That being said, it is important to examine current policies of both academic and public libraries, and the state of developing collections to meet the needs of VI users.

Schmetzke et al. (2014) state that accessible information environments are best achieved when libraries adopt a policy that includes accessibility in selection criteria, includes accessibility "during the selection process," discusses accessibility with vendors, and provides "feedback to vendors about the reasons why a product got selected or not (especially if accessibility was a factor)" (p. 172). Furthermore, librarians should consider accessibility a requirement in the licensing agreement. According to Blechner (2014), discussions with vendors should always consist of how the product will benefit the library and its patrons. This includes the discussion of vendor Voluntary Product Accessibility Templates (VPATs). The purpose of VPATs is for vendors to publicly state the capabilities of products and efforts put forth to meet the accessibility requirements stated in Section 508 of the Rehabilitation Act. However, according to the United States General Services Administration (n.d.), compliance applies to federal agencies or those directly associated with them. In order for vendors to conduct business with federal agencies or affiliates, they must present a VPAT either publicly or upon request. The request and use of VPATs in procurement for librarians in general should be considered, although there has been criticism around the usefulness and clarity of them. As Blechner (2014) suggests, libraries and other organizations can certainly hire qualified third parties to draft adequate VPATs to use during licensing discussions with vendors, but this option likely depends on the cost. Overall, libraries must possess a large degree of accessibility awareness; an awareness often not mentioned in collections textbooks or training material for students and practicing librarians (Schmetzke et al., 2014). This, however, leads one to question the current approaches to accessibility stated in library collections policies.

\section{Academic Libraries}

In their research, Schmetzke et al. (2014) found that out of 24 smaller academic libraries surveyed for inclusion of accessibility in their collection policies, Sonoma State University was the only school to include accessibility. Taking a look at some additional academic libraries outside of this study, it is 
evident that other academic libraries have either continued or began addressing accessibility in their collections. Iowa State University (ISU) (2019-a) states in its collection development policy that it makes every effort to select and acquire electronic resources that will accommodate users with disabilities, as well as the entire campus community (para. 8). One of the most important aspects of ISU's statement is it clearly states that the selection and acquisitions process has ongoing discussion with vendors about the accessibility of electronic formats for their users. ISU's stated efforts in ongoing discussion with vendors suggests a consciousness toward negotiating license agreements. In a separate accessibility statement for the ISU digital repository, there is a link to their own approved VPAT that outlines the components of how they work to provide the most accessible web content for their users. This statement provides insight into the ISU's standards for accessibility. How this translates to the negotiation of license agreements and the procurement of library resources is not directly known, but it reinforces the accessibility awareness factor.

Montana State University (MSU) provides a similar statement in their policy, but they interestingly make it a point to include exceptions to altered formats. MSU (2019) states that it goes to lengths to ensure the most "web accessible resources" (para. 25), as well as to make information gathering and the acquisition of electronic resources a priority. Considering the recent ratification of the Marrakesh Treaty, MSU's exception in their statement reflects the issue of altering the formats of copyright material that has existed for some time. Unlike ISU, MSU's website does not appear to provide any information on their own VPAT. However, there is evidence of awareness when it comes to accessibility and negotiations with vendors during the procurement process. In 2015, former MSU librarian, Kirsten Ostergaard, wrote an article entitled Accessibility from Scratch: One Library's Journey to Prioritize the Accessibility of Electronic Information Resources. This article specifically addressed the issue of accessibility of electronic resources at MSU, and the approaches in moving forward. At the time, Ostergaard (2015) quoted the same accessibility statement that appears in MSU's current collection development policy updated September, 2019. However, she highlights MSU's understanding of how vendor communication impacts the procurement process for electronic resources. This includes discussing accessibility, requesting VPATs from vendors, inquiring about alternate file formats, requiring proper accessibility language in license agreements, and negotiations with vendors around converting inaccessible resources into accessible ones. According to Ostergaard (2015), MSU is also committed to improving their collection development policy when it learns of new developments in accessibility. Given that MSU's accessibility statement has not changed since at least 2015, it perhaps indicates a standstill in progress regarding altered formats.

The University of Queensland (UQ) in Australia provides a statement in their collection management policy that practically mirrors the policy from MSU, including the exception of altering formats. Unlike the MSU policy, and even ISU, it explicitly directs its efforts in securing accessible formats toward VI users 
(UQ, 2019). Like the United States, Australia is one of 63 countries that ratified the Marrakesh Treaty. However, being that UQ's collection development policy was also updated in the latter part of 2019, it raises questions around what might be holding up the process of format alteration. According to Browne (2018), Australia has amended its copyright law in 2017 to redefine persons with disabilities to include those with print disabilities. Furthermore, it also allows for not-for-profit institutions (e.g., educational institutions) to create alternate formats. As there is no such thing as international copyright law, one can surmise that the most logical reason for delay is attributed to the long process of amending and restructuring copyright laws in other countries participating in the treaty. In other words, although Australians might be able to make format adjustments to resources under Australian copyright laws, restrictions still apply elsewhere. For example, in the United States, the NLS confirmed in May of 2019 that they are still waiting for legal revisions to be made in order to begin sharing accessible formats (NLS, 2019).

From the above statements, one can see the potential within academic libraries to make special considerations to the accessibility of collections when it comes to users with disabilities. However, it must be noted that the aforementioned policies were selected based on their consideration of users with disabilities. Many others considered in the research for this paper either did not specifically include users with disabilities, or only briefly mentioned their consideration of varying formats. For example, Colorado State University (n.d.) states that its libraries recognize the importance in providing resources to their users in varying formats, as well as with varying technologies when necessary. Louisiana State University Libraries' (2018) statement is quite generic, as their policy generally supports "the information needs to the campus academic community..." (para. 2). Additional research, however, can determine the role of accessibility, and the impact all of these policies have on VI users in campus communities, regardless of their current statements. As a review of academic library collection policies can provide a brief look into the state of collections and accessibility, it is dually important to see how the public library sector takes on the same task.

\section{Public Libraries}

Academic and public libraries certainly have their differences when it comes to the audience and the types of collections they build. However, an important component of successful collecting is that "accessibility should be an essential requirement when selecting e-resources" (Johnson, 2018, p. 128). In fact, the earlier principles suggested by Schmetzke et al. can be applied to public libraries as well.

The Oshawa Public Libraries (OPL) in Ontario, Canada provide a comprehensive collection development policy that lays out the goals of collection building in order to support the libraries' mission. Not only does the policy explain the need to generate a collection of formats that adheres to the needs of the community, it explicitly states that its collection goal is to include "formats to 
facilitate equity of access to persons with print disabilities" (OPL, 2019, para. 4). In order to do this, the OPL seeks the ability to provide access and makes arrangements for accessible resources "where they exist in the marketplace" (OPL, 2019, para. 5), and in compliance with existing legislation. Prior to Canada's ratification of the Marrakesh Treaty, their copyright laws already allowed for the creation of materials in accessible formats. This makes Canada one of the more progressive nations in terms of creating accessible formats. The law, however, excludes the creation of varying formats for the purpose of wide distribution and monetary profit (Ontario Council of University Libraries, n.d.). Rather than require institutions to be approved to create accessible formats, the implications in the Canadian law simply require individuals and institutions to act in support of one's "perceptual disability" (Ontario Council of University Libraries, n.d., para. 3). In other words, the creation of accessible formats must be conducted by an individual with a visual impairment or physical disability, or by a non-profit institution acting in support of said individual

The Detroit Public Library (DPL) also provides a clear statement in its collection development policy informing users that a part of its goal is to provide "resources in special formats devised to meet the needs of the vision-impaired, the hearing-impaired, and others whose disabilities impede their ability to make optimum use of other Library resources" (DPL, n.d., para. 45). Further down the policy, the DPL notes its compliance with the United States Copyright Law Code Title 17, Sections 107 and 108, which include the ability for "transformation and reproduction of copyrighted works specifically for customers with disabilities" (DPL, n.d., para. 70). However, the lack of updates to sections of this policy (e.g., 1980, 1996) is concerning, and might explain the omission of the Chafee Amendment in its copyright statement. At the very least, it tells us about the accessibility awareness of the DPL, and its mission to provide access to VI users and other users with disabilities over time.

The Oxford County Library (OCL) in Ontario, Canada presents a somewhat different take in their policy, which states that in order to broaden the scope of the collection and also develop a larger collection for users with print disabilities, the library will take part in consortia and "accessible format initiatives" (OCL, 2018, para. 10). Although consortia are valuable collaborative efforts to enhance the information needs of communities, to be effective means establishing absolute clarity in the mission and goals, understanding the users and their needs, and ensuring the collections can be delivered and accessed (e.g., adequate technologies) in a timely manner (Johnson, 2018). It is not clear which consortia OCL has approached or plans to approach about accessibility for VI users, but its short statement suggests that the library system is paying attention.

Similar to the approach in reviewing academic library collection policies, it was also found that there is a small amount of public library policies available that explicitly present their stance on selection and users with disabilities, let alone VI users specifically. This, however, does not indicate that libraries do not have policies that adhere to laws of accessibility overall. In many cases, academic and public libraries create separate policies that address the needs of users with 
disabilities that include facility access, as well as technologies that will allow them to access collections. For example, the Syracuse University Libraries include an accessibility policy that addresses assistive technologies, requests for alternate formats, and assistance services for technology use and resource retrieval (Syracuse University Libraries, n.d.). The New York Public Library addresses the needs of VI users, specifically, in their accessibility policy with a list of available technologies, resources (e.g., talking books), and workshops (New York Public Library, 2019). However, there still lies a question as to whether these policies are indeed considered in the selection process, or whether it is to be assumed. To reiterate Schmetzke et al. (2014), successful accessible information environments come with the inclusion of accessibility in the selection policy, and half of the battle is knowing what products and tools are available to achieve this.

\section{Formats and Products}

As mentioned in the introduction to this paper, technological advancements continue to enhance the efforts to improve accessible information environments. For VI users, the format of a resource is the backbone of electronic information access. These formats often come in the form of audio, but can often be converted to large print and braille. Rayini (2017) states that audio formats are among the most popular used by VI users, and usually come in the form of talking books. Historically, these formats consisted of cassettes and vinyl records, but the days of analog formats are dwindling as digital formats have been taking over.

One of the largest consortiums to tackle this change is the Digital Accessible Information System (DAISY), which was established to "develop an international standard and software to produce talking books digitally" (Rayini, 2017, p. 9). Books formatted under DAISY offer advanced navigation capabilities, which assists VI users to pinpoint certain chapters, pages, use the index, and bookmark sections to return to. To access these books, however, VI users must also have access to compatible devices that support the format.

Other formats to consider for reader tools are Electronic PUBlication (EPUB), which is often a format used for Amazon Kindle and Barnes \& Noble Nook readers, and Microsoft Word document files. Although Word document files are not a prime format for most talking books, many academic sources are generated using this format (Junus, 2012). VI users seeking large print books will find that libraries do collect physical books in this format. However, many e-books will allow users to adjust the font size or zoom in for appropriate viewing. Additionally, even braille formats have entered the digital age with the use of translation software that can convert formats for braille printing, text scanning that can be translated into braille code, and Braille Refreshable Format (BRF) files. The latter format is compatible with braille reading devices (Rayini, 2017). As understanding the variety of formats is important during the selection process, knowing where to access these formats is vital to building the collection overall. 


\section{Bookshare}

As previously mentioned, Bookshare has the largest collection of accessible books in the world. With more than 748,000 titles, the collection covers a variety of subject areas that suit the interests of VI users, such as students, working professionals, and recreational readers. In addition, this extensive library offers titles in over 34 different languages (Bookshare, 2019-a). What makes this extensive library most accessible to VI users are the formats offered in the collection. Items can be retrieved as DAISY, EPUB, BRF, and Word documents, which will support the varying needs of VI users using varying devices. Bookshare is free for United States schools and other organizations (e.g., public libraries). The only requirement is that users must prove their eligibility for access (Bookshare, 2019-b).

\section{Gale In Context}

Gale In Context suite is a host to several subject databases that are designed to meet the needs of a diverse population. This product contains "on-demand text and translation into 12 languages," and is designed to accommodate VI users with low vision to complete blindness with its text-to-speech technology (Gale, 2019). Collections librarians considering this product for the collection should consult the vendor about all possible alternate formats for the VI users they are seeking to serve.

\section{Non-VI User Specific Products}

It is clear that there are not a plethora of electronic options for VI users, currently. However, there are additional products that exist, which contain features that potentially meet the needs of VI users. Products such as EBSCO and ProQuest host numerous databases that cover a variety of subject areas. However, as the features vary, collections librarians must discuss accessibility options with the vendors prior to making a purchase or marketing resources as accessible to all users. For e-books, there are many products out there that contain vast collections that cover a variety of subject interests. Overdrive, Mackin, and Hoopla are just a few of the products out there purchased by libraries. For VI users, Overdrive books can be read with better accommodations through the use of the Adobe Digital Editions app and applicable screen readers (Adobe, 2019). Along with discussing accessibility and features with vendors, Johnson (2018) states that collections librarians should always map out their purchases, and create a set of criteria that must be used when considering the products they wish to purchase.

\section{Conclusion}

This paper made an attempt to uncover a current state of electronic resource accessibility for VI users through an exploration of the challenges, developments, collections policies, as well as current formats and available products. It is evident that VI users are still at a disadvantage, as the amount of products and technological capabilities cannot exactly mirror the experience of users without

print disabilities. Current formats for many electronic resources prevent tools 
from interpreting documents the way non-VI users can, and heavy copyright laws have inhibited this development. However, the developments in law and the Marrakesh Treaty show a progression toward copyright reform across the globe. This reform will eventually remove barriers that are currently preventing libraries and vendors from offering the formats needed to create truly accessible information environments. This paper also found that academic and public libraries are currently sparse with their inclusion of accessibility for users with disabilities in their collections policies. The lack of standard regarding collection statements is concerning, despite separate accessibility policies and statements. The separation of these policies creates confusion as to whether some libraries truly consider accessibility and users with disabilities in the selection process. The current language in collections policies suggests that there is still some ambiguity around active collecting practices, as it relates to VI users. Despite the policy statements in this study that include a degree of accessibility awareness, the statements, alone, do not measure actual procurement or resource impact on VI users. In other words, although some libraries lack accessibility language in a policy, it does not necessarily indicate a lack of awareness regarding accessibility issues. A review of policy statements, however, is a starting point in raising questions around active procurement of accessible materials, and who may or may not be involved in taking action toward improving accessible information environments. Therefore, future research should examine active procurement of accessible materials for VI users, how influential policies have been in that process, and the success rate of procurement based on varying barriers. However, this study has also revealed information that provides hope for the future. Organizations like Bookshare have bridged gaps for VI users in the world of ebooks. Their success in providing ebooks in varying formats and languages has opened up a world of literature to VI users. At the same time, it provides us with questions of how this can translate to other electronic resources (e.g., academic journals), so one day information accessibility will not be a question for anyone. 


\section{References}

Abbott, N. (2019). Marrakesh treaty in action. Library Journal, 144(4). Retrieved from

https://www.libraryjournal.com?detailStory=Marrakesh-Treaty-in-Action

Adobe. (2019). Features of Adobe Digital Editions. Retrieved from https://www.adobe.com/solutions/ebook/digital-editions.html.

Alford, Duncan E. (2002). Negotiating and analyzing electronic license agreements. Law Library Journal, 94(4), 621-644. Retrieved from https://scholarcommons.sc.edu/law facpub/237/.

Blechner, A. (2015). Improving Usability of Legal Research Databases for Users with Print Disabilities. Legal Reference Services Quarterly, 34(2), 138-175. DOI: https://doi.org/10.1080/0270319X.2015.1048647

Bookshare. (2019-a). About us. Retrieved from https://www.bookshare.org/cms/about.

Bookshare. (2019-b). What does it cost? Retrieved from https://www.bookshare.org/cms/Bookshare-me/what-does-it-cost.

Browne, D. (2018, January 9). Australia-copyright law reform update-a lot to celebrate and look forward to. Creative Commons Australia. Retrieved from https://creativecommons.org.au/blog/2018/01/australia-copyright-law-refo rm-update-a-lot-to-celebrate-and-a-lot-to-look-forward-to/.

Centre for Equitable Library Access. (2019). Services for public libraries. Retrieved from https://celalibrary.ca/public-libraries.

Ciccone, M. (2018). Equitable public library services for Canadians with print disabilities. Reference Services Review,46(3), 379-398. DOI: https://doi.org/10.1108/RSR-04-2018-0041.

Colorado State University. (n.d.). Collection development policies. Retrieved from https://lib.colostate.edu/about/contact-us/library-departments/collectionsmanagement/collection-development-policies/.

Detroit Public Library. (n.d.). Collection development. Retrieved from https://detroitpubliclibrary.org/policies/collection-development.

Fitzpatrick, S. (2014). Setting its sights on the Marrakesh Treaty: The U.S. role in alleviating the book famine for persons with print disabilities. Boston College International and Comparative Law Review, 37(1), 139-172. Retrieved from https://lawdigitalcommons.bc.edu/iclr/vol37/iss1/6/.

Gale. (2019). Gale In Context. Retrieved from https://www.gale.com/intl/databases/gale-in-context.

Harpur, P., \& Loudoun, R. (2011). The barrier of the written word: Analysing universities' policies to students with print disabilities. Journal of Higher Education Policy and Management, 33(2), 153-167. DOI: https://doi.org/10.1080/1360080X.2011.550088. 
Iowa State University. (2019-a). Collection development policy. Retrieved from https://www.lib.iastate.edu/about-library/policies/collections-development collection-development-policy.

Iowa State University. (2019-b). Iowa State digital repository: Accessibility statement. Retrieved from https://lib.dr.iastate.edu/accessibility.html.

Junus, S.G. R. (2012). E-books and e-readers for users with print disabilities.

Library Technology Reports, 48(7), 22-28. Retrieved from https://journals.ala.org/index.php//tr/article/view/4683/5567.

Johnson, P. (2018). Fundamentals of collection development and management, (4th ed.). Chicago: American Library Association.

Louisiana State University. (2018). Collection development policy statement. Retrieved from https://www.lib.lsu.edu/collections/policies/statement.

Majinge, R., \& Mutula, S. (2018). Access to electronic and print information resources by people with visual impairments in university libraries. Library Management,39(6-7), 462-473. Retrieved from https://www.emerald.com/insight/content/doi/10.1108/LM-04-2017-0038/ full/html.

Montana State University. (2019). Collection development policy. Retrieved from https://www.lib.montana.edu/collections/cdpolicy/.

National Library Service. (n.d.). Overview. Retrieved from https://www.loc.gov/nls/about/overview/.

National Library Service. (2019). National Library Service Marrakesh Treaty implementation. Retrieved from

https://www.loc.gov/nls/about/organization/ laws-regulations/marrakesh-treaty/.

Olwan, R. (2017). The ratification and implementation of the Marrakesh Treaty for visually impaired persons in the Arab Gulf States. Journal of World Intellectual Property, 20(5-6), 178-205. DOI: https://doi.org/10.1111/jwip. 12088.

Ontario Council of University Libraries. (n.d.). Canadian copyright and accessibility. Retrieved from https://ocul.on.ca/accessibility/law-and-administration/canadian-copyright $\#$ sect3.

Oshawa Public Libraries. (2019). Collection development policy. Retrieved from http://www.oshawalibrary.on.ca/sites/all/pdf/bylaws/Collection-Development-Pol icy.pdf.

Ostergaard, K. (2015). Accessibility from scratch: One library's journey to prioritize the accessibility of electronic information resources. The Serials Librarian, 69(2), 155-168. Retrieved from https://scholarworks.montana.edu/xmlui/bitstream/handle/1/9341/Ostergaard K_Accessibility_Postprint 2015.pdf? sequence $=1$.

Oxford County Library. (2018). Collection development policy. Retrieved from https://www.ocl.net/Portals/OxfordCountyLibrary/Documents/policies/Collection \%20Development\%20Policy\%202018.pdf. 
Rayini, J. (2017). Library and information services to the visually impaired persons. Library Philosophy and Practice, 2017. Retrieved from https://digitalcommons.unl.edu/libphilprac/1510/

Schmetzke, A., Pruitt, C., and Bruno, M. (2014). Collection development, e-resources, and meeting the needs of people with disabilities.

Proceedings of the Charleston Library Conference. West Lafayette, IN:

Purdue University Press. DOI: https://dx.doi.org/10.5703/1288284315579.

Syracuse University Libraries. (n.d.). Accessibility. Retrieved from https://library.syr.edu/accessibility/index.php.

United Nations. (2019). World population prospects 2019. New York: United Nations Retrieved from https://www.who.int/blindness/GLOBALDATAFINALforweb.pdf.

United States Copyright Office. (2019). Understanding the Marrakesh Treaty Implementation Act. Retrieved from https://www.copyright.gov/legislation/2018 marrakesh faqs.pdf.

University of Queensland. (2017). Collection management policy. Retrieved from https://web.library.uq.edu.au/collections/collection-management/collection-manag ement-policy.

World Health Organization. (2019, October 8). Blindness and vision impairment. Retrieved from

https://www.who.int/en/news-room/fact-sheets/detail/blindness-and-visual-impair ment. 